\title{
Coronary steal syndrome after coronary artery bypass for anomalous aortic origin of a coronary artery.
}

\author{
Benjamin A. Youdelman \\ Thomas Jefferson University \\ Glenn J. Pelletier \\ Thomas Jefferson University \\ C Igor Mesia \\ Thomas Jefferson University \\ Marshall L. Jacobs \\ Thomas Jefferson University
}

Follow this and additional works at: https://jdc.jefferson.edu/surgeryfp

Part of the Surgery Commons

Let us know how access to this document benefits you

\section{Recommended Citation}

Youdelman, Benjamin A.; Pelletier, Glenn J.; Mesia, C Igor; and Jacobs, Marshall L., "Coronary steal syndrome after coronary artery bypass for anomalous aortic origin of a coronary artery." (2009). Department of Surgery Faculty Papers. Paper 18.

https://jdc.jefferson.edu/surgeryfp/18

This Article is brought to you for free and open access by the Jefferson Digital Commons. The Jefferson Digital Commons is a service of Thomas Jefferson University's Center for Teaching and Learning (CTL). The Commons is a showcase for Jefferson books and journals, peer-reviewed scholarly publications, unique historical collections from the University archives, and teaching tools. The Jefferson Digital Commons allows researchers and interested readers anywhere in the world to learn about and keep up to date with Jefferson scholarship. This article has been accepted for inclusion in Department of Surgery Faculty Papers by an authorized administrator of the Jefferson Digital Commons. For more information, please contact: JeffersonDigitalCommons@jefferson.edu. 


\section{THEANNALS OF}

\section{Coronary Steal Syndrome After Coronary Artery Bypass for Anomalous Aortic Origin of a Coronary Artery}

Benjamin A. Youdelman, Glenn J. Pelletier, C. Igor Mesia and Marshall L. Jacobs Ann Thorac Surg 2009;87:1292-1295

DOI: 10.1016/j.athoracsur.2008.07.099

The online version of this article, along with updated information and services, is located on the World Wide Web at:

http://ats.ctsnetjournals.org/cgi/content/full/87/4/1292 
the patient was brought to the intensive care unit. The postoperative creatine kinase-MB fraction was $11.04 \mathrm{ng} /$ $\mathrm{mL}$, and the patient was discharged from the hospital on postoperative day 4 . A follow-up computed tomographic scan with contrast at 1 month confirmed that there was no flow into the aneurysm and that it was stable in size. At 1-year follow-up the patient is doing well and has no complaints.

\section{Comment}

Several possible treatments were considered for this patient including coil embolization, median sternotomy to ligate the graft, a small lateral thoracotomy to dissect the vein graft from the sternum, followed by a median sternotomy, as well as our innovative approach to patch the ostia of the graft from within the aorta. In several cases, endovascular coiling has been used to avoid more invasive procedures [2-5]; however, these aneurysms were significantly smaller

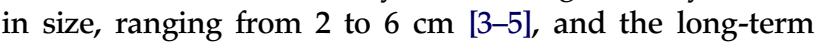
durability of this approach is unknown. Although several studies reported successful outcomes, $[2,3,5]$ recurrence within 6 months has been reported [4].

The patient's previous history of two coronary artery bypass graft procedures, location of the pseudoaneurysm, and dependence on the patent bypass grafts increased the risk of surgical intervention through a median sternotomy. Performing a small lateral thoracotomy to dissect structures from beneath the sternum, followed by a standard sternotomy has been described [6]. However, we were concerned that dissection of the thinwalled pseudoaneurysm under limited visibility could have caused potential injury; therefore, we were reluctant about this approach.

Performing a thoracotomy and placing the patient on circulatory arrest is associated with some risk [7]; however, these risks were weighed against the potential injury of the patent grafts or pseudoaneurysm. We believed that our approach was best, allowing for prevention of rupture and keeping the patent grafts intact. This method is limited by the inability to re-graft the area supplied by the pseudoaneurysm; however, in the absence of angina or congestive heart failure symptoms, we believed that addressing the acute issue (ie, the enlarging vein graft aneurysm) and by continuing to medically manage the coronary artery disease, it was a prudent treatment plan. Many authors [8] believe that replacement of patent vein grafts greater than 5 years old should be tailored to the individual patient based on diagnosis and remaining conduit. For this patient, after two coronary artery bypass graft operations, there was not a usable length of saphenous vein remaining. Although the right internal mammary artery was still intact, as demonstrated by the computed tomographic scan, the vein graft aneurysm displaced the pericardial contents, making placement of the right internal mammary to the anterior or lateral wall impossible. Therefore, to preserve the patent grafts and prevent rupture of the vein graft aneurysm, we used this novel approach eliminating blood flow into the vein graft aneurysm while preserving the other grafts.

\section{References}

1. Dieter R, Patel A, Yandow D, et al. Conservative vs invasive treatment of aortocoronary saphenous vein graft aneurysms: treatment algorithm based upon large series. Cardiovasc Surg 2003;11:507-13.

2. Le Breton H, Pavin D, Langanay T, et al. Aneurysms and pseudoaneurysms of saphenous vein coronary artery bypass grafts. Heart 1998;79:505-8.

3. Rogers J, Chang D, Lasala J. Percutaneous repair of coronary artery bypass graft-related pseudoaneurysms using covered JOSTENTs. J Invasive Cardiol 2003;15:533-5.

4. Bosmans J, Claeys M, Dilling D, et al. Unsuccessful long-term outcome after treatment of a vein graft false aneurysm with a polytetrafluoethylene-coated jostent. Cathet Cardiovasc Intervent 2000;50:105-8.

5. Hameed A, Hanna-Moussa S, David S. Use of multiple stents to seal off an epicardial pseudoaneurysm. J Invasive Cardiol 2003;15:405-7.

6. O'Brien MF, Harrocks S, Clarke A, et al. How to do safe sternal reentry and the risk factors of redo cardiac surgery: a 21-year review with zero major cardiac injury. J Card Surg 2002;17:4-13.

7. Gega A, Rizzo J, Johnson M, et al. Straight deep hypothermic arrest: experience in 394 patients supports its effectiveness as a sole means of brain preservation. Ann Thorac Surg 2007;84: 759-67.

8. Gonzalez-Stawinski GV, Lytle BW. Coronary artery reoperations. In: Cohn LH, Edmunds LH Jr, eds. Cardiac surgery in the adult, 3rd ed. New York, NY: McGraw-Hill, 2008:711-32.

\section{Coronary Steal Syndrome After Coronary Artery Bypass for Anomalous Aortic Origin of a Coronary Artery}

Benjamin A. Youdelman, MD, Glenn J. Pelletier, MD, C. Igor Mesia, MD, and Marshall L. Jacobs, MD

Division of Cardiothoracic Surgery, Department of Surgery, Thomas Jefferson University, Departments of Cardiothoracic Surgery and Pediatric Cardiology, Drexel University College of Medicine, Philadelphia, Pennsylvania

Anomalous aortic origin of a coronary artery found in a symptomatic 9-year-old boy was initially treated with coronary artery bypass grafting using a left internal mammary artery anastomoses to the left anterior descending coronary artery, but resulted in coronary ischemia, likely from a steal phenomenon. Subsequent transection of the proximal left internal mammary artery with anastomosis to the ascending aorta, and coronary ostial enlargement, resulted in a durable treatment. We recommend caution in choosing coronary artery bypass grafting using a left internal mammary artery pedicle graft for the treatment of anomalous aortic origin of a coronary artery.

(Ann Thorac Surg 2009;87:1292-5)

(C) 2009 by The Society of Thoracic Surgeons

Accepted for publication July 29, 2008.

Address correspondence to Dr Youdelman, Division of Cardiothoracic Surgery, Department of Surgery, Thomas Jefferson University, 1025 Walnut St, Suite 607, Philadelphia, PA 19107; e-mail: benjamin. youdelman@jefferson.edu. 
$\mathrm{A}$ nomalous aortic origin of a coronary artery (AAOCA) has been associated with signs and symptoms of myocardial ischemia, and may be a cause for sudden death in children and young adults [1, 2].

Anatomic variations include the left main coronary artery arising from the right sinus of Valsalva, and the right coronary artery arising from the left sinus. Theories to explain the mechanism for myocardial ischemia are varied. They include stenosis or distortion of the coronary ostium, compression of an intramural coronary segment subjected to high aortic wall tension, kinking at the acute angle of the proximal anomalous coronary during hyperdynamic conditions, or compression of the coronary artery between the aortic and pulmonary roots during effort-related expansion of these vessels [3]. With the pathophysiology imprecise, it follows that the surgical approached to AAOCA has been varied.

Numerous operations have been proposed to treat this condition including coronary artery bypass surgery (CABG) with arterial or venous conduits, reimplantation of the coronary artery into the appropriate sinus of Valsalva [4], and coronary ostial enlargement with or without unroofing of an intramural segment [5]. Currently there is no consensus for surgical treatment.

Risk of sudden death in a patient with AAOCA is believed to be reduced by creating durable, unobstructed coronary artery flow. The recommendation for surgery in adolescents or young adults is generally made when signs or symptoms of myocardial ischemia are present, but are less well-defined when the coronary anomaly is discovered incidentally in asymptomatic infants or young children.

We report a 9-year-old boy who presented with syncope preceded by palpitations, dizziness, and diaphoresis. Similar symptoms occurred 4 years earlier, and palpitations are reported with exercise.

His electocardiogram showed sinus arrhythmia, a prolonged Q-T interval of $461 \mathrm{msec}$, but no ischemia. He underwent echocardiography that revealed anomalous origin of the left coronary artery from the right coronary sinus of Valsalva. Computerized tomographic angiography and cardiac catheterization demonstrated the left coronary artery coursing between the aorta and pulmonary trunk. No intramural course was identified.

Coronary artery bypass grafting surgery using the left internal mammary artery (LIMA) pedicle graft connected to the left anterior descending coronary artery was performed. After separation from cardiopulmonary bypass, the hemodynamics were good. However, when the chest retractor was removed, diffuse ST segment elevation occurred and the patient had ventricular tachycardia. The graft was inspected and found to have a palpable

Two videos of this procedure can be viewed on the Internet at: http://ats.ctsnetjournals.org/content/vol87/ issue4/images/data/1292/DC1/youdelman1.mpg and http://ats.ctsnetjournals.org/content/vol87/issue4/images/ data/1292/DC1/youdelman2.mpg.

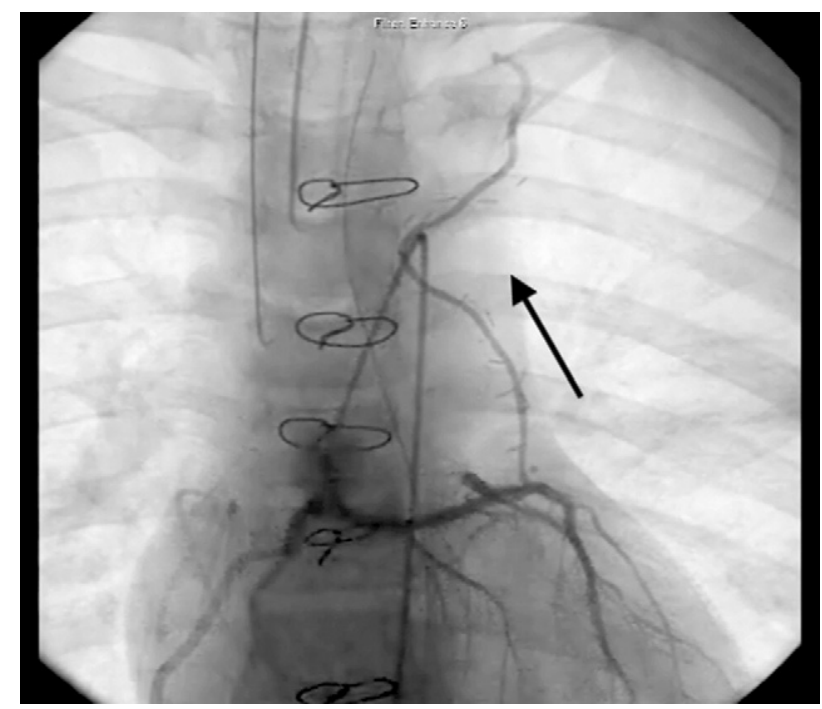

Fig 1. Initial postoperative coronary angiogram showing anomalous origin of the left coronary artery from the right coronary sinus of Valsalva. Retrograde flow from the left anterior descending coronary artery to the left internal mammary artery to the left subclavian artery was seen (arrow shows direction of flow).

pulse. Echocardiography showed normal cardiac function without segmental wall motion abnormalities. The patient was transported to the cardiac catheterization laboratory for emergent angiography.

Initial injection into the left subclavian artery showed poor filling of the LIMA graft; however, direct injection into the LIMA filled the entire coronary circulation. Injection into the right sinus of Valsalva uniformly filled both right and left coronary systems, but retrograde flow from the left anterior descending coronary artery through the LIMA and into left subclavian artery demonstrated a steal circuit diverting blood from the left anterior descending coronary artery territory (Fig 1; video 1 viewable at http://ats.ctsnetjournals.org/content/vol87/ issue4/images/data/1292/DC1/youdelman1.mpg). The patient returned to the operating room for surgical revision.

Opening the chest widely again reduced the ischemic changes on electrocardiogram, but occlusion of the LIMA did not resolve them. Therefore, the attention was directed to the coronary artery origin.

The aortic root was explored and a single coronary ostium was identified. The right coronary artery arose from the ostium and traveled in its usual course. The left coronary artery exited from within the single ostium in an oblique fashion. No intramural course was identified. The obliquity of the left coronary origin seemed to create a point of coronary stenosis, and this opening was enlarged by incising it into the aortic media and then repairing it.

The patient was weaned from circulatory support with good hemodynamics and no ischemic changes on electrocardiogram. However, again with removal of the chest retractor, the ischemic phenomenon recurred even with the LIMA graft occluded. 


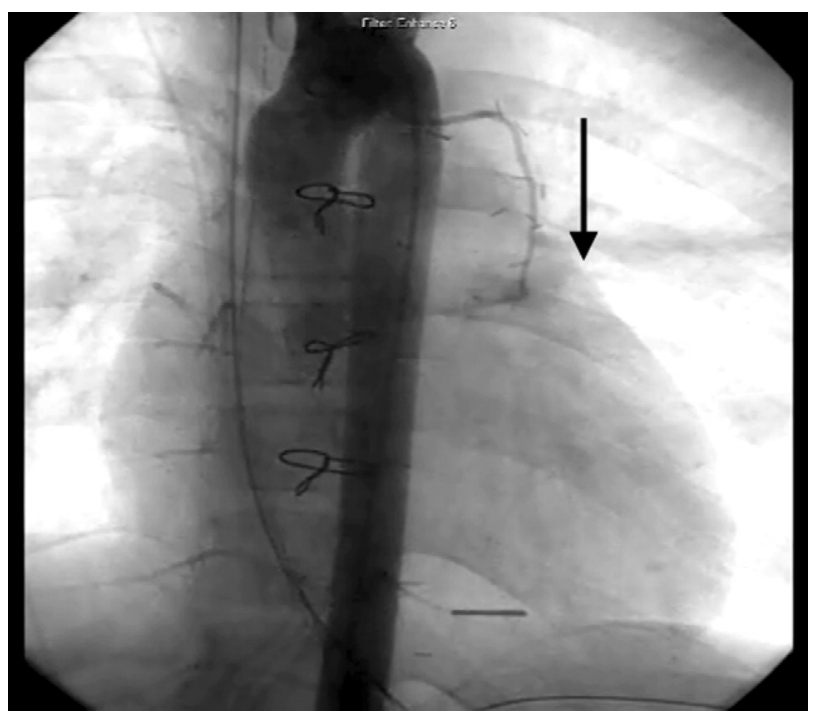

Fig 2. Ascending aortogram after the aorto-left internal mammary artery (LIMA) anastomosis done at the second operation. Antegrade flow from the aorta to the free LIMA into the left anterior descending coronary artery was seen (arrow shows direction of flow).

We hypothesized that transferring the LIMA to the ascending aorta would increase the perfusion pressure enough to improve flow through the LIMA graft and relieve the steal syndrome. After completion of the LIMA to the aorta proximal anastomosis, when the chest retractor was removed this time, there was less pronounced ST elevation in the lateral electrocardiogram leads and only rare premature ventricular complexes (PVC). The electrocardiographic measurements showed that normal sinus rhythm remained and the mild ST elevations improved in time.

The day after surgery, transthoracic echocardiography was normal. A repeat angiogram showed the left coronary ostial repair to be patent with unobstructed antegrade flow. The flow in the distal LIMA graft was biphasic. Injection in the ascending aorta showed antegrade flow into the LAD from the LIMA graft (Fig 2; video 2 viewable at http://ats.ctsnetjournals.org/content/vol87/ issue4/images/data/1292/DC1/youdelman2.mpg). The coronary steal was no longer present.

A troponin level on postoperative day 1 was $12.2 \mathrm{ng} / \mathrm{mL}$, but it decreased to $3.6 \mathrm{ng} / \mathrm{mL}$ by postoperative day 4 . One week after surgery he underwent a stress test using a modified Bruce protocol. No ischemic changes or arrhythmias were observed. In follow-up, he is well and free of signs and symptoms of coronary artery insufficiency.

\section{Comment}

Patients who have anomalous left coronary arteries that come from a single ostium and course between the great arteries are at risk for sudden death [1]. The first reported bypass grafting for an aberrant left coronary artery was done in 1977 using a saphenous vein bypass from the aorta to the left main coronary artery [6]. The internal mammary artery has been favored for CABG in children because of superior patency rates as compared with saphenous vein grafts and its ability to grow with the child [7].

Internal mammary artery steal syndrome after coronary bypass operations is rare in adults and is usually associated with subclavian artery stenosis [8]. Steal syndrome associate with internal mammary artery grafting in children has not previously been reported.

In this case, we hypothesize that ischemia after CABG using a pedicle LIMA graft occurred when impingement on the left subclavian artery or proximal LIMA graft was relieved by removal of the chest retractor. Without the obstruction to flow, runoff through the LIMA into the left subclavian artery, away from the coronary circulation occurred, producing a steal phenomenon. That occlusion of the LIMA graft on return to the operating room did not completely resolve the ischemic changes on electrocardiogram and may be a consequence of the myocardium having been ischemic for several hours and not having had adequate recovery time.

Although CABG for surgical treatment of AAOCA has been advocated by some, the experience with this patient demonstrates a shortfall of this approach. Internal mammary artery steal for a LIMA pedicle graft is a real phenomenon that can be created when two patent vessels supply blood flow to a common end artery. Relative resistances of the vascular beds at either end of the LIMA will determine flow through this graft. It would be unlikely to predict a case of steal syndrome using a LIMA graft without the presence of proximal left subclavian artery stenosis, which has been seen in adults [8]. Based on this experience, we recommend caution in choosing CABG using a LIMA pedicle graft for the treatment of AAOCA.

Many thanks to Jill Kaiser for preparing the images for this report.

\section{References}

1. Maron BJ, Roberts WC, McAllister HA, Rosing DR, Epstein SE Sudden death in young athletes. Circulation 1980;62:218-29.

2. Taylor AJ, Byers JP, Cheitlin MD, et al. Anomalous right or left coronary artery from the contralateral coronary sinus: "highrisk" abnormalities in the initial coronary artery course and heterogeneous clinical outcomes. Am Heart J 1997;133:428-35.

3. Yamanaka O, Hobbs RE. Coronary artery anomalies in 126,595 patients undergoing coronary arteriography. Cathet Cardiovasc Diagn 1990;21:28-40.

4. Cohen AJ, Grishkin BA, Helsel RA, Head HD. Surgical therapy in the management of coronary anomalies: emphasis on utility of internal mammary artery grafts. Ann Thorac Surg 1989;47:630-7.

5. Romp RL, Helong R, Landolfo CK, et al. Outcome of unroofing procedure for repair of anomalous aortic origin of left or right coronary artery. Ann Thorac Surg 2003;76:589-96.

6. Sacks JH, Londe SP, Rosenbluth A, Zalis EG, Judkins MP. Left main coronary bypass for aberrant (aortic) intramural left coronary artery. J Thorac Cardiovasc Surg 1977;73: 733-7. 
7. Isomura T, Hisatomi $\mathrm{K}$, Hirano A, Ohishi $\mathrm{K}$, Inoue $\mathrm{O}$, Kato $\mathrm{H}$. The internal thoracic artery and its branches after coronary artery anastomoses in pediatric patients. J Card Surg 1992; 225-30.

8. Hennen B, Markwirth T, Scheller B, Schafers HJ, Wendler O. Impaired flow in left internal mammary artery grafts due to subclavian artery stenosis. Ann Thorac Surg 2001; 72:917-9.

\section{Combination of Aortopulmonary Window and Complete Atrioventricular Septal Defect in a Patient With Heterotaxy Syndrome}

\author{
Mohammad Reza Mirzaaghayan, MD, \\ Reza Shabanian, MD, and Abdolrazagh Kiani, MD
}

Department of Cardiac Surgery, Imam Hospital, and Department of Pediatric Cardiology, Children's Medical Center, Tehran University of Medical Sciences, Tehran, Iran

A rare combination of aortopulmonary window and complete atrioventricular septal defect diagnosed in a 2-monthold infant with heterotaxy syndrome is presented. Being aware of this combination of cardiac anomalies before surgical intervention is crucial for perioperative anesthetic technique and preservation of the myocardium.

(Ann Thorac Surg 2009;87:1295-6) (C) 2009 by The Society of Thoracic Surgeons

A ortopulmonary (AP) window and complete atrioventricular septal defect (AVSD) are cardiovascular defects that may occur alone, although they are associated with other cardiac anomalies. The combination of both defects was reported in a 3-month-old infant described by McElhinney and colleagues in 2000 [1]. Here we describe a 2-month-old infant with coexisting AP window and complete AVSD in association with heterotaxia, a rare combination of congenital cardiovascular defects.

A nondysmorphic 2-month-old boy ( $3.5 \mathrm{~kg})$ was referred to us for surgical intervention because of little improvement in his growth and intractable cardiac failure despite optimal medical management. At age 3 weeks he was evaluated for cardiac anomaly because of tachypnea and poor feeding. The echocardiography demonstrated a complete AVSD (Rastelli type C) with unbalanced ventricles (the right ventricular type), a left-sided superior caval vein draining through an enlarged coronary sinus, and a right aortic arch. Although a retrograde review of echocardiographic video images confirmed an AP window, it was not diagnosed preoperatively. The infant also had a midline liver with equally sized lobes.

The operation was initiated through a midsternotomy, but cardiac arrest suddenly occurred while the sternotomy was being performed. We rapidly completed the

Accepted for publication Aug 13, 2008.

Address correspondence to Dr Shabanian, Children's Medical Center, 62 Gharib St, Tehran, 14194, Iran; e-mail: rshabanian@gmail.com. sternotomy, and open cardiac massage was begun. The external cardiac anatomy was evaluated, and a type I AP window (Richardson classification) of about $5 \mathrm{~mm}$ in diameter was noted. To have the highest cardiac output during cardiopulmonary resuscitation, we clamped the right pulmonary artery.

Cardiopulmonary resuscitative measures were not successful, and cardiopulmonary bypass was initiated. The patient was cooled to $20^{\circ} \mathrm{C}$. The aorta and pulmonary arteries were separated, and the resultant aortic and pulmonary arterial defects were each closed with two separate pericardial patches. The pulmonary artery was banded.

Unfortunately, the patient could not be weaned from bypass by either a tight or loose band because of very poor contractility. The autopsy confirmed all echocardiographic findings and also bilateral trilobed lungs with eparterial bronchi, asplenia, and a symmetrical liver.

\section{Comment}

The embryogenesis of AP window is related to incomplete fusion or malalignment of the right and left conotruncal ridges, which normally completely septate the truncus arteriosus between the fifth and eighth weeks of intrauterine life. The division of the truncus arteriosus into separate aortic and pulmonary channels is influenced by cells that migrate from the neural crest [2]. This influence may explain the association of AP window with various arterial abnormalities, including transposition of the great arteries and aortic interruption. Other associated congenital cardiac anomalies with AP window are anomalous origin of a coronary artery, ventricular septal defect, atrial septal defect, patent ductus arteriosus, pulmonary or aortic atresia, tricuspid atresia, right aortic arch, pulmonary venous stenosis, and persistent left superior caval vein to coronary sinus [2]. However, an AP window is not seen when the neural crest is removed [3]. In addition, AP window has not been reported in association with DiGeorge syndrome [4, 5].

Partitioning of the AV canal begins about the middle of the fourth week of gestation and is essentially complete by the end of the fifth week. Concurrent with atrial septation, thickenings of subendocardial tissue, called endocardial cushions, develop in the dorsal and ventral walls of the heart in the region of the AV canal. Therefore, abnormal growth in this region produces a deficiency in the lowermost part of the atrial septum and also a VSD.

Because the dextrodorsal conus cushion contributes to the development of the right $\mathrm{AV}$ valve and the outflow tracts lie adjacent to their respective inflow tracts, AVSDs may be associated with conotruncal anomalies, such as tetralogy of Fallot and double-outlet right ventricle. Like in patients with AP window, neural crest ablation in embryonic avian models almost never results in anomalies of the AV junction [6].

AVSDs are also associated with other cardiac defects, including heterotaxy syndromes, total anomalous pulmonary venous return, transposition of great arteries, patent 


\section{Coronary Steal Syndrome After Coronary Artery Bypass for Anomalous Aortic Origin of a Coronary Artery}

Benjamin A. Youdelman, Glenn J. Pelletier, C. Igor Mesia and Marshall L. Jacobs Ann Thorac Surg 2009;87:1292-1295

DOI: 10.1016/j.athoracsur.2008.07.099

Updated Information \& Services

References

Subspecialty Collections

Permissions \& Licensing

Reprints including high-resolution figures, can be found at:

http://ats.ctsnetjournals.org/cgi/content/full/87/4/1292

This article cites 7 articles, 5 of which you can access for free at: http://ats.ctsnetjournals.org/cgi/content/full/87/4/1292\#BIBL

This article, along with others on similar topics, appears in the following collection(s):

Congenital - acyanotic

http://ats.ctsnetjournals.org/cgi/collection/congenital_acyanotic

Requests about reproducing this article in parts (figures, tables) or in its entirety should be submitted to:

http://www.us.elsevierhealth.com/Licensing/permissions.jsp or email: healthpermissions@elsevier.com.

For information about ordering reprints, please email: reprints@elsevier.com 